\title{
A DRYINID PARASITE ATTACKING BALDULUS MAIDIS IN PUERTO RICO
}

By K. A. Bartletw, Associate Entomologist, Puerto Rico Experiment Station, United States Department of Agriculture.

An interesting parasite of the corn leafhopper, Baldulus maidis (Del. and W.), ${ }^{1}$ was observed at Mayagüez, Puerto Rico, during August 1937, by Wallace K. Bailey, Associate horticulturist at this, the Federal Experiment Station, who called it to the attention of the writer. Following observations, collections were made and material reared for determination. The parasite was found to be a new species of Gonatopus very near G. bicolor Ashm., known to attack Baldulus maidis in the United States. Observations were apparently made on the parasite in 1912 by T. H. Jones (1), who reared specimens of a new species of Gonatopus from cocoons collected on cane leaves. Wolcott (1) records the finding of Baldulus maidis parasitized by a blue-green strepsipteron, which might easily have been mistaken for the larval sac of this dryinid parasite.

This parasite is antlike in appearance; the adult females are wingless. The forelegs of the female are especially adapted to the catching and holding of the leafhopper while inserting an egg in the dorsal side of the abdomen. After oviposition the leafhopper is released and the parasite begins development. A wartlike protrusion develops on the abdomen of the leafhopper. This protrusion is a portion of the body of the parasite larva partially enveloped in cast skins. When the parasite larva becomes full-fed the leafhopper dies and remains attached to the under side of the leaf for at least a short period. During this time the parasite larva detaches itself from its host and spins a white. flat, oval cocoon nearby on the leaf or stalk of the plant. From this cocoon the adult parasite later on emerges.

Collections of living leafhoppers in the field showed a parasitization by Gonatopus of 15 percent. The effectveness of the parasite is somewhat reduced by a hyperparasite which attacks the cocoons. Specimens of this hyperparasite were reared and identified as Ooencyrtus n. sp. ${ }^{2}$

1 Identification by P. W. Oman, Bureau of Entomology and Plant Quarantine.

z Identification by A. B. Gahan, Bureau of Entomology and Plant Quarantine. 
THE JOURNAL OF AGRICULTURE OF THE UNIVERSITY OF P. $R$.

\section{Literature Cited}

(1) Wolcott, George N. "Insectae Borinquenses". The Journal of Agriculture of the University of Puerto Rico, 20 (1):498, January 1936. 